NASCIMENTO et al., v(10), no 10, p. 2233-2250, JAN-ABR, 2013.

Rev. Elet. em Gestão, Educação e Tecnologia Ambiental (e-ISSN: 2236-1170)

\title{
COLETA SELETIVA SOLIDÁRIA: UMA EXPERIÊNCIA DESENVOLVIDA NO CAMPUS DE PESQUISA DO MUSEU PARAENSE EMÍLIO GOELDI (MPEG), BELÉM-PA
}

\section{Selective Collection Solidarity: an experience developed at Research Campus Goeldi Museum (MPEG), Belém-PA}

\author{
Rosana Oliveira Nascimento', Gilma Isabel Rêgo D’Aquino², Amilcar Carvalho Mendes ${ }^{3}$, Maria de \\ Lourdes Pinheiro Ruivo ${ }^{4}$, Liane Hissae Tashiro ${ }^{5}$ \\ ${ }^{1}$ Graduada em Ciências Sociais pela Universidade da Amazônia (UNAMA). Especialização em Educação Ambiental pela \\ Universidade Federal do Pará (UFPA). Bolsista do Programa de Capacitação Profissional (PCI) do Museu Paraense \\ Emílio Goeldi (MPEG). rosananascimento63@gmail.com \\ 2 Pesquisadora do Museu Paraense Emílio Goeldi. gilma@museu-goeldi.br \\ ${ }^{3}$ Pesquisador do Museu Paraense Emilio Goeldi. amendes@museu-goeldi.br \\ ${ }^{4}$ Pesquisadora do Museu Paraense Emílio Goeldi. ruivo@museu-goeldi.br \\ ${ }^{5}$ Bolsista de Iniciação Científica - PIBIC/Museu Paraense Emilio Goeldi. liana hissae@hotmail.com
}

http://dx.doi.org/10.5902/223611707889

\section{RESUMO}

O presente trabalho, de caráter descritivo, relata uma experiência piloto que tem como objetivo apresentar a metodologia utilizada para implantação do Programa de Coleta Seletiva Solidária, no Campus de Pesquisa do Museu Paraense Emilio Goeldi, bem como os principais resultados qualitativos e quantitativos dos materiais recicláveis produzidos na instituição. A coleta de dados foi realizada por meio de um diagnóstico da situação e entrevista individuais semi estruturadas com funcionários e colaboradores terceirizados que atuam no serviço de limpeza, sobre o processo de separação dos materiais recicláveis, para verificar como era realizada a separação, acondicionamento e o destino dos mesmos às cooperativas. Foi realizado seminário sobre a temática e treinamento para funcionários terceirizados responsáveis pela limpeza. A análise quantitativa e qualitativa dos materiais recicláveis produzidos no Campus de Pesquisa foi realizada mediante separação, classificação e pesagem dos materiais recicláveis (papel, papelão, plásticos, vidros e metais), produzidos no âmbito das coordenações de pesquisa e na área externa da instituição. O resultado mostrou que no Campus de Pesquisa é gerada, anualmente, uma carga de resíduos recicláveis de aproximadamente $5.600 \mathrm{~kg}$, o que contribui para beneficiar cooperativas que recebem esses materiais. A experiência subsidiou a expansão do Programa de Coleta Seletiva Solidária para as demais bases físicas da instituição e, sobretudo, para mensurar, ainda que preliminarmente, a contribuição das matérias recicláveis produzidos no âmbito da instituição no orçamento e para a melhoria da qualidade de vida dos catadores.

Palavras- chave: Resíduos Sólidos, Coleta Seletiva, Educação Ambiental.

\section{ABSTRACT}

This descriptive study reports a pilot experiment that aims to present the methodology used to implement the Selective Collection Solidarity Program, at Research Campus in the Emilio Goeldi Museum of Pará, as well as the main qualitative and quantitative results of recyclables produced 


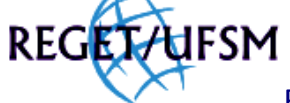

NASCIMENTO et al., v(10), no 10, p. 2233-2250, JAN-ABR, 2013.

Rev. Elet. em Gestão, Educação e Tecnologia Ambiental (e-ISSN: 2236-1170)

at the institution. Data collection was conducted through a diagnosis of the situation and individual semi-structured interviews with employees and outsourced employees working in housekeeping, about the process of separation of recyclable materials, as was done to check the separation, packaging and destination of these cooperatives. Seminar was held on the issue and training for contractors employees responsible for cleaning. The quantitative and qualitative analysis of recyclable materials produced in Campus Research was performed by separating, sorting and weighing of recyclable materials (paper, cardboard, plastics, glass and metals), produced under the research coordination and in the area outside the institution. The result showed that in the Research Campus is generated, annually, a load of recyclable waste from approximately $5,600 \mathrm{~kg}$, which helps to benefit cooperatives that receive these materials. The experience subsidized the expansion of Selective Collection Solidarity Program to the other physical bases of the institution and especially to measure, even preliminarily, the contribution of recyclable materials produced within the institution and in the budget to improve the quality of life of scavengers.

Keyword: Solid Waste, Selective Collection, Environmental Education.

\section{INTRODUÇÃO}

Lixo é tudo aquilo que as pessoas descartam, não querem mais ou, ainda, aquilo que não tem mais utilidade e é colocado em local público, muitas vezes sabendo que sua presença é prejudicial à saúde (CALDERONI, 1999).

No Brasil, são produzidas cerca de 47.450 mil toneladas de lixo por ano (BLEY JR, 2001). Nos últimos anos, tem sido verificado um aumento desse volume superior a $10 \%$ ao ano (COZETTI, 2001). Há várias maneiras de diminuir o volume de lixo destinado aos aterros, como incineração, digestão anaeróbia, compostagem, coleta seletiva ou separação pós-coleta.

Materiais recicláveis compõem, em média, 35\% do lixo nas cidades brasileiras, percentual que deveria ser retornado ao mercado consumidor via reciclagem, diminuindo os impactos ambientais causados pelo grande volume de lixo descartado no meio (GRADVOHL, 2001). Segundo Bianchini (2001), a reciclagem de materiais usados constitui-se em uma das principais soluções e, seguramente, a que mais possibilita a inclusão social do contingente de trabalhadores que atuam na atividade de catação. Cabe ressaltar que a reciclagem já é uma realidade no país, atingindo índices invejáveis para alguns produtos, como latas de alumínio.

Um processo de extrema importância para o sucesso da reciclagem é a coleta seletiva de lixo, que compreende a separação e coleta de materiais recicláveis na fonte geradora (VILHENA \& D'ALMEIDA, 2000). Segundo Neiva (2001), o principal problema enfrentado para o crescimento da reciclagem dos diversos tipos de materiais é a inexistência ou a ineficiência de programas de coleta seletiva.

No Brasil, o Governo Federal instituiu a separação dos resíduos recicláveis descartados pelos órgãos e entidades da administração pública federal direta e indireta, na fonte geradora, e a sua destinação às associações e cooperativas de catadores de materiais recicláveis, segundo regulamentação pelo (Decreto № 5940, de 25 de outubro de 2006). Trata-se de um programa governamental que busca a construção de uma cultura institucional para um novo modelo de gestão dos resíduos, no âmbito da administração pública federal direta e indireta, somada aos princípios e metas estabelecidas pela Agenda Ambiental da Administração Pública Federal. 


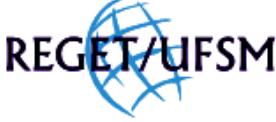

NASCIMENTO et al., v(10), no 10, p. 2233-2250, JAN-ABR, 2013.

Rev. Elet. em Gestão, Educação e Tecnologia Ambiental (e-ISSN: 2236-1170)

Segundo Aguiar (1994) um programa institucional que possa servir de exemplo para diminuir os resíduos lançados no aterro e contribuir para a geração de emprego e renda, deve ser papel de toda instituição que se preocupa com o meio ambiente. Estas ações viabilizam a utilização de recursos públicos para outras áreas, aumentando a vida útil dos aterros, melhora a qualidade de vida da população e, principalmente, minimizam o impacto causado à natureza.

De acordo com MMA (2007), essa ação do governo tem um cunho social e ambiental ao mesmo tempo, já que incentiva a geração de emprego e renda para os catadores e evita que esses materiais sejam desperdiçados. Portanto, esta política de resíduos sólidos além de gerar renda e inclusão social, com a criação de emprego para milhares de pessoas, supre outras importantíssimas demandas, como: diminuição da carga de resíduos destinadas aterros e lixões (minimizando diversos impactos ambientais) e economia de energia na fabricação de produtos com o uso das matérias primas reciclados e outras.

Assim, os órgãos públicos federais da administração direta e indireta tiveram 120 dias, a partir da data de publicação do Decreto no 5.940, para implantar a coleta seletiva solidária de resíduos sólidos em suas repartições. Em atendimento a essa diretriz e consciente de que a questão ambiental deve estar no cerne do desenvolvimento de qualquer atividade no mundo atual, o Museu Paraense Emílio Goeldi instituiu em 2007 o Programa de Coleta Seletiva Solidária em cumprimento ao Decreto Lei. Essa proposta tem como objetivo a separação seletiva dos resíduos sólidos recicláveis gerados pelas atividades administrativas e de pesquisa desenvolvidas pela instituição e sua correta destinação socioambiental, contribuindo para a inclusão socioeconômica dos catadores de materiais recicláveis, valorizar e fortalecer essa mão-de-obra por intermédio de associações e cooperativas, além da gestão ecologicamente correta dos resíduos sólidos gerados na instituição

O presente trabalho objetiva, então, apresentar a metodologia utilizada para implantação do Programa de Coleta Seletiva Solidária - PCSS, no Campus de Pesquisa do Museu Paraense Emilio Goeldi (MPEG), bem como os principais resultados qualitativos e quantitativos dos materiais recicláveis produzidos na instituição.

\section{HISTÓRICO DO PROGRAMA DE COLETA SELETIVA SOLIDÁRIA (PCSS) NO MPEG}

O PCSS, a nível federal, é desenvolvido sob a égide do Comitê Interministerial de Inclusão Social dos Catadores de Materiais Recicláveis (CIISC), coordenado pelo Ministério do Desenvolvimento Social e Combate à Fome (MDS) e o Ministério das Cidades (MC). Este Comitê foi criado por Decreto Federal em 11/09/2003, para articular ações em todos os órgãos federais, viabilizar a organização de catadores em todo país e, assim, contribuir para melhorar a qualidade de vida desses trabalhadores.

O CIISC, através do Aviso Interministerial no 02, de 27/12/06, encaminhado a todos os ministros de estado e dirigentes de órgãos federais, solicitou a implementação do Decreto-Lei №. 5.940, de 25 de outubro de 2006,

Em 28 de outubro de 2007 foi emitida a Ordem Interna de no 043/2007, nomeando os membros da Comissão Interna responsável pela implementação do Programa de Coleta Seletiva Solidária no Museu Paraense Emílio Goeldi (MPEG), consumando, desta forma, a adesão institucional à determinação e esforço do Governo Federal. 


\section{REGEJAUFSM}

NASCIMENTO et al., v(10), no 10, p. 2233-2250, JAN-ABR, 2013.

Rev. Elet. em Gestão, Educação e Tecnologia Ambiental (e-ISSN: 2236-1170)

\section{SÍTIO-PILOTO}

O Campus de Pesquisa do MPEG, localizado na cidade de Belém-PA, ocupa uma área de12 hectares (Figura 1), onde estão instalados dezesseis (16) prédios, abrigando as Coordenações de Pesquisa (Botânica-CBO, Zoologia-CZO, Ciências Humanas-CCH, Ciências da Terra e Ecologia-CCTE), Coordenação de Informação e Documentação (CID), Coordenação de Planejamento (CPA), Biblioteca Domingos Soares Ferreira Penna, Coleções Científicas e Laboratórios Institucionais.

Nesta base física circulam atualmente um contingente composto por cento e oitenta (180) funcionários, cento e dez (110) bolsistas, setenta e quatro (74) estagiários e cento e sete (107) alunos vinculados aos programas de pós-graduação.

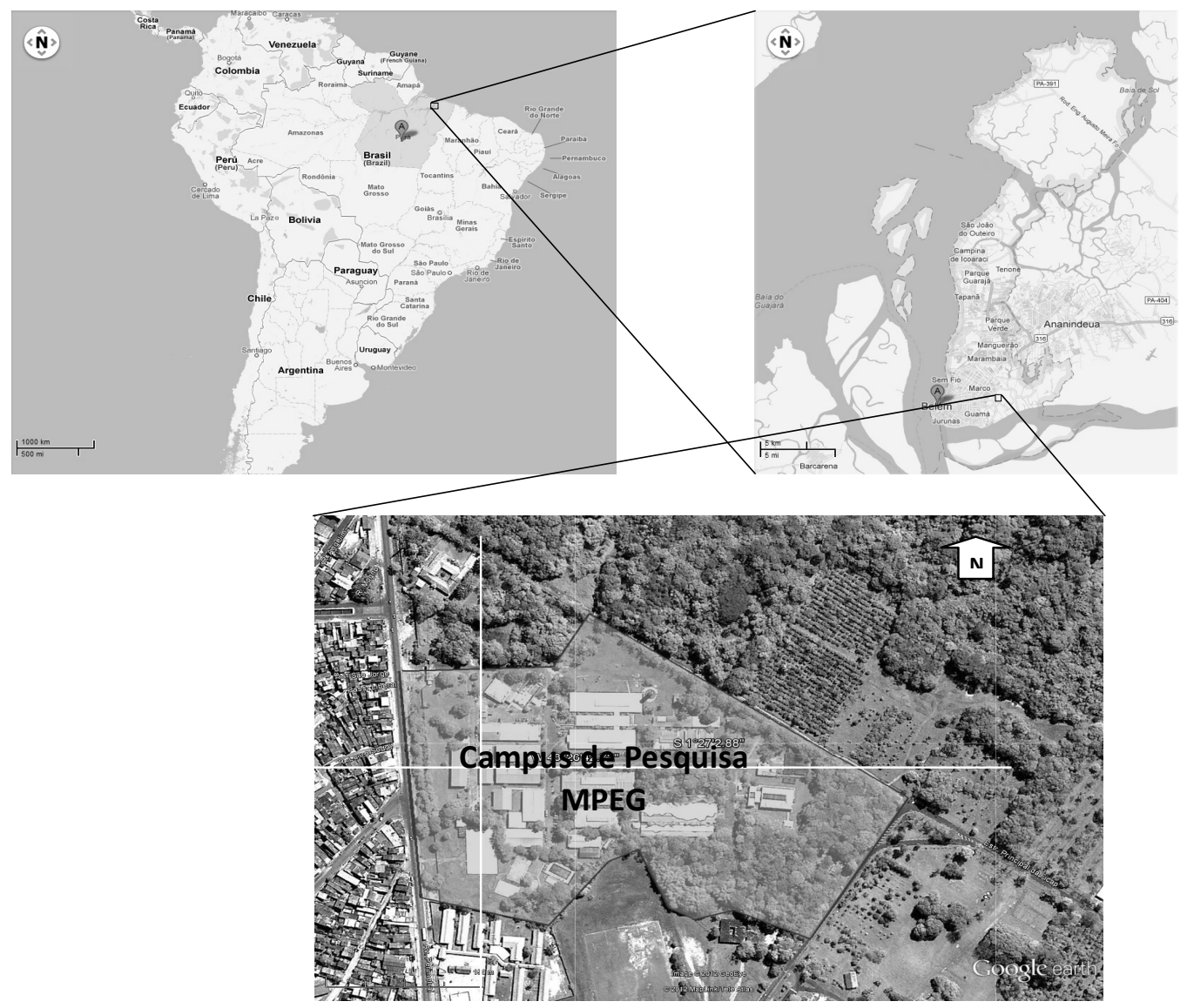

Figura 1: Localização do Campus de Pesquisa do MPE

\section{METODOLOGIA DE IMPLANTAÇÃO DO PROGRAMA DE COLETA SELETIVA SOLIDÁRIA NO CAMPUS DE PESQUISA DO MPEG}

A caracterização dos materiais recicláveis por coordenação (figura 2 e 3) foi realizada em maio de 2010, visando verificar qual dos departamentos aderiu com eficácia a CSS, a fim de 


\section{REGEJAUFSM}

NASCIMENTO et al., v(10), no 10, p. 2233-2250, JAN-ABR, 2013.

Rev. Elet. em Gestão, Educação e Tecnologia Ambiental (e-ISSN: 2236-1170)

avaliaar e acompanhar o desempenho, considerando-se as peculiaridades de cada uma das coordenações e de seus sujeitos.
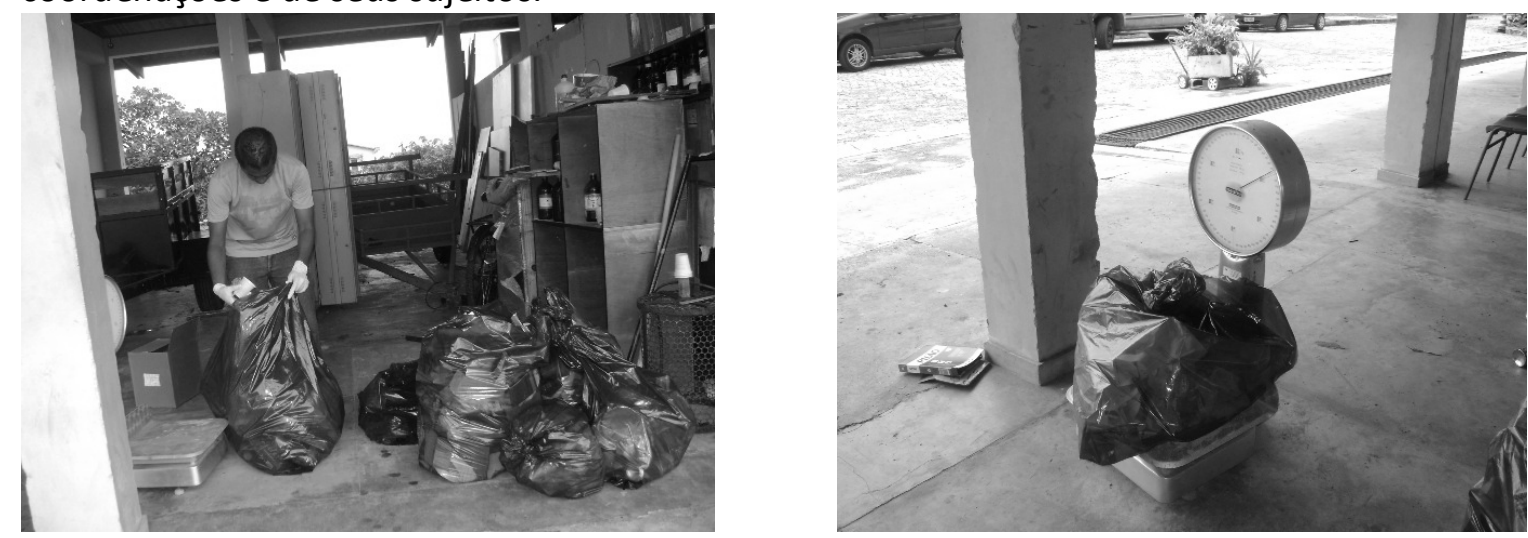

Figura 2,3: Caracterização dos Materiais recicláveis do Campus de pesquisa do MPEG e a Balança utilizada para passagem

A pesagem dos resíduos sólidos foi realizada com materiais acumulados em duas semanas, que foram separados e pesados para verificar o peso real de todos os materiais produzido por cada coordenação do Campus de Pesquisa do MPEG, considerando apenas os dias úteis, tendo em vista que nos fins de semana não há expediente. Os materiais encontrados foram: plástico, papel, papelão, alumínio e vidros.

A metodologia utilizada pode ser classificada como eminentemente descritiva, uma vez que teve como ponto de partida uma observação não estruturada, ou seja, assistemática, pois consistiu, em um primeiro momento, em recolher e registrar os fatos da realidade sem fazer uso de meios técnicos especiais. Esse primeiro passo lançou as bases para a definição da proposta metodológica, cujas etapas estão sumarizadas no fluxograma apresentado na Figura 4. 


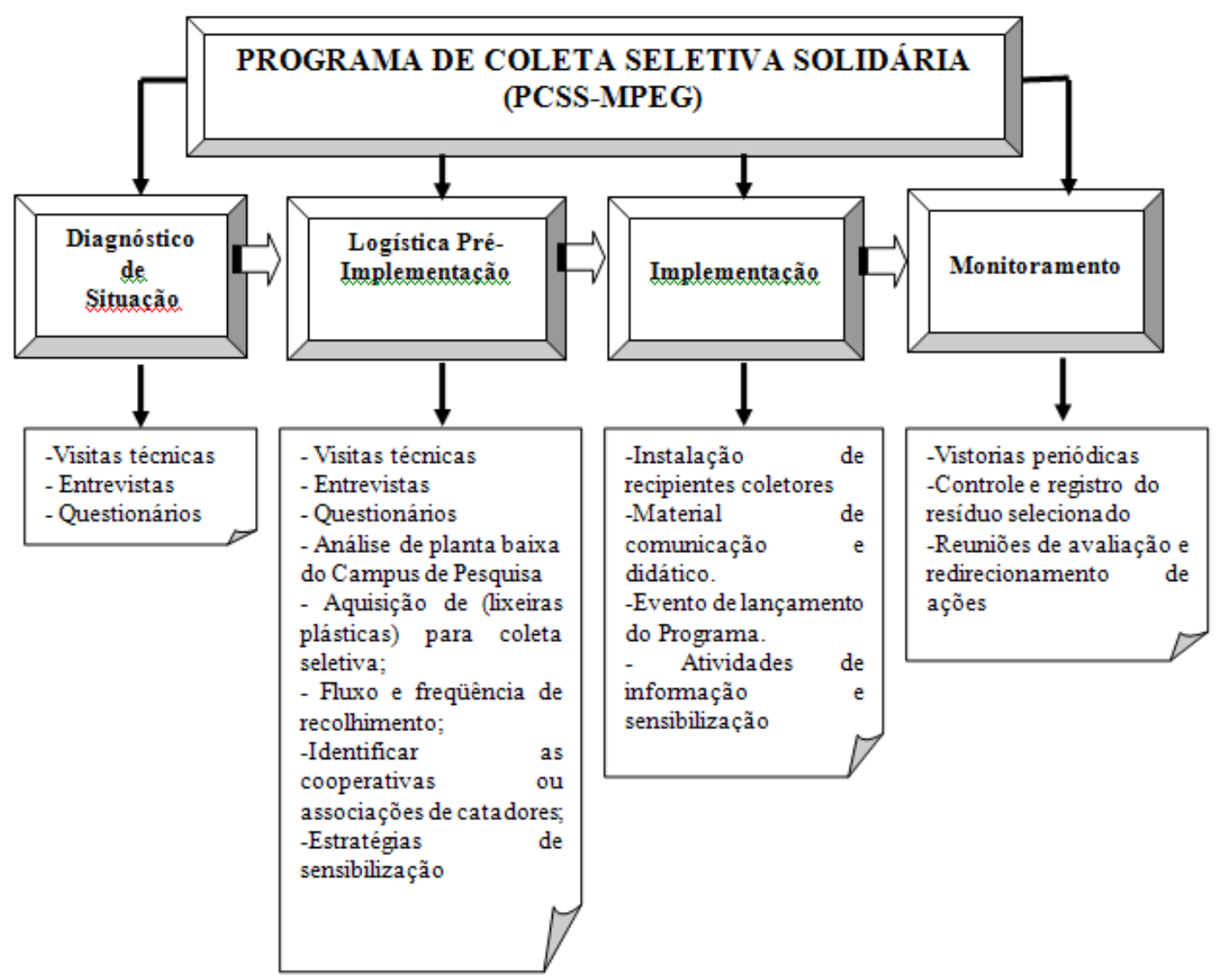

Figura 4: Fluxograma das etapas metodológicas para implantação do PCSS no Campus de Pesquisa do Museu Paraense Emílio Goeldi

\subsection{Diagnóstico de Situação}

O diagnóstico foi realizado por meio de entrevistas diretas, com perguntas abertas e fechadas, em questionário aplicado a quarenta funcionários (pesquisadores e pessoal técnicoadministrativo) e a vinte prestadores de serviços terceirizados que atuam na limpeza do Campus de Pesquisa do MPEG.

O objetivo foi verificar de que maneira os resíduos sólidos coletados eram processados (fluxo e freqüência de recolhimento), quantificados, qual a forma, local de acondicionamento e destinação final dos resíduos. Além disso, o diagnóstico objetivou definir qual a percepção dos entrevistados sobre o Programa de Coleta Seletiva Solidária.

\subsection{Logística Pré-Inplementação do PCSS}

No período de janeiro de 2009 a julho de 2010 foi realizado levantamento de dados referentes à produção e infraestrutura disponível para coleta, separação e destinação final dos resíduos produzidos no Campus de Pesquisa, para fins de estabelecer o estágio zero e diagnóstico 


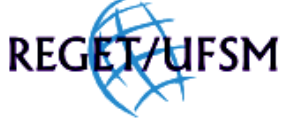

NASCIMENTO et al., v(10), no 10, p. 2233-2250, JAN-ABR, 2013.

Rev. Elet. em Gestão, Educação e Tecnologia Ambiental (e-ISSN: 2236-1170)

da situação pré-implantação do Programa de Coleta Seletiva Solidária. Os principais passos metodológicos desta etapa foram:

- Levantamento de dados sobre a situação da produção (qualitativa e quantitativa) de resíduos em cada setor (administrativo e de pesquisa) para identificar os principais materiais potencialmente recicláveis (papéis, plásticos, vidros, etc...) utilizados em cada unidade;

- Análise da planta baixa do Campus de Pesquisa para fins de elaboração do plano de distribuição dos recipientes externos para a coleta seletiva, bem como do local para acondicionamento de materiais recicláveis recolhidos;

- Análise da planta interna dos prédios para definição de locais para instalação de recipientes internos de coleta seletiva;

- Aquisição de recipientes para coleta seletiva em ambiente externo (corredores, passarelas, pátios externos, garagem, etc....) e interno (salas, laboratórios, biblioteca, herbário, salas de coleções científicas, etc....);

- Definição do fluxo e freqüência do recolhimento dos materiais recicláveis;

- Identificação das cooperativas ou associações de catadores que atendessem aos critérios estabelecidos no Decreto Federal 5.940/2006. Ao mesmo tempo, identificação do interesse/viabilidade e capacidade das mesmas em receber e processar os materiais selecionados;

- Definição de estratégias e materiais de sensibilização (cartazes, folders, cartilhas, vídeos, palestras, apresentações lúdicas, divulgação na intranet, etc...) para o público-alvo (servidores, prestadores de serviços terceirizados, estudantes de pós-graduação, bolsistas, estagiários, freqüentadores da biblioteca, funcionários da cantina e visitantes.

\subsection{Implantação e execução do Programa de Coleta Seletiva Solidária}

Para a consecução desta etapa foram realizadas as seguintes ações:

- Distribuição e instalação dos recipientes coletores de materiais recicláveis em áreas internas e externas;

- Distribuição do material de comunicação e didático nas diferentes coordenações e departamentos do Campus de Pesquisa;

- Realização do evento de lançamento do Programa de Coleta Seletiva Solidária;

- Desenvolvimento permanente das atividades de informação e sensibilização para o público-alvo;

\subsection{Monitoramento}

As ações empreendidas nessa etapa foram:

- Vistorias periódicas para verificação do cumprimento das rotinas estabelecidas para a seleção, coleta e destinação de materiais recicláveis;

- Controle e registro do material selecionado e coletado;

- Reuniões bimensais para identificação de fatores facilitadores e dificultadores do programa e reformulação de estratégias, com redirecionamento das ações, quando necessário. 


\subsection{Treinamento dos funcionários terceirizados}

No treinamento foi evidenciado o conteúdo do Decreto Lei 5.940/2006, a importância de atendê-lo e o compromisso dos mesmos no desenvolvimento da coleta seletiva solidária na instituição. Essa atividade foi desenvolvida no horário normal de expediente, havendo a dispensa de funcionário terceirizados para a realização do trabalho.

Com a implantação do programa da CSS no MPEG surgiram convites para realização de palestras relatando a experiência da CSS. Os convites partiram de instituições privadas de ensino superiores, escolas públicas e comunidades. Também foram ministradas palestras de educação ambiental para a terceira idade e crianças; oficinas de materiais recicláveis; e seminários dentre outros eventos organizados em parceria com a instituições como:

- Instituto Tecnológico e Ambiental da Amazônia (ITAM) - I e II Seminário de Meio Ambiente

- Faculdade Metropolitana da Amazônia (FAMAZ), no âmbito do Ciclo de palestras de Saúde Ambiental Faculdade Ideal (FACl),

- Centro de Estudo Superior do Pará (CESUPA)

- Universidade do Estado do Para (UEPA).

Ações internas e externas são desenvolvidas continuamente através de eventos organizados na instituição como os "Seminários Temáticos de Resíduos Sólidos, Coleta Seletiva e Responsabilidade Socioambiental", que contou com a participação de 300 (trezentos) inscritos, entre docentes, discentes, catadores das cooperativas, pesquisadores, funcionários terceirizados, estudantes/bolsistas, assim como membros da comunidade do entorno da instituição.

Atividades realizadas no dia mundial de Meio Ambiente com a plantação de mudas, oficina de produção de sabão a partir do reaproveitamento de óleo de cozinha, exposição de vídeos sobre resíduos sólidos, reciclagem e meio ambiente, palestra com o tema Água e o Planeta e peça teatral. O evento contou com a presença de 100 participantes entre estudantes, professores, funcionários e bolsistas da instituição. Oficinas, com a temática Educação Ambiental, Meio Ambiente e sobre artesanatos confeccionados a partir dos materiais recicláveis produzidos na instituição, evidenciando-se o reaproveitamento (reciclagem), a sustentabilidade e a mudança de comportamento diante da produção do lixo; a importância dessas ações para a conservação do ambiente natural e para manutenção das vidas no planeta

\section{RESULTADOS E DISCUSSÕES}

\subsection{Diagnósticos de Situação}

Antes da implantação do Programa de Coleta Seletiva Solidária foi desenvolvida uma ação de aproveitamento de material reciclável, na qual os prestadores de serviços terceirizados que atuavam na limpeza do Campus de Pesquisa faziam a separação, recolhimento e estocagem de resíduos recicláveis (papel, vidro, papelão, plástico, alumínio). Esse material era posteriormente, vendido a terceiros e a renda obtida ao longo do ano era dividida entre os mesmos ou para compra de eletrodomésticos para serem sorteados por ocasião da confraternização natalina, representando, assim, significativo reforço no orçamento familiar desses funcionários. 
NASCIMENTO et al., v(10), no 10, p. 2233-2250, JAN-ABR, 2013.

Rev. Elet. em Gestão, Educação e Tecnologia Ambiental (e-ISSN: 2236-1170)

\subsection{Logística de Pré-Instalação do PCSS no MPEG}

Em 09 de julho de 2007 o Departamento de Inclusão Social (DIS) do MCTI, ministrou treinamento com demonstração da separação dos materiais recicláveis e não recicláveis aos funcionários de serviços gerais e pesquisadores do MPEG, incluindo a distribuição de cartilhas com as estratégias e instruções para a implantação da coleta seletiva solidária nas instituições públicas federais.

Com base nas informações repassadas no treinamento foi elaborada a estratégia para a sensibilização do público-alvo. Esta foi baseada em diretrizes norteadoras da pesquisa-ação participativa, que possibilitam articular a ação educativa com a participação efetiva dos envolvidos, de forma a torná-los geradores de reflexão sobre o ambiente, contribuindo para o processo de conscientização do público-alvo sobre a importância da coleta seletiva solidária na instituição e para a sociedade.

Ainda no âmbito das estratégias de sensibilização, foi elaborado um plano de divulgação/conscientização que envolveu a produção de cartazes, folders, cartilhas, socialização de vídeos, ciclo de palestras, apresentações lúdicas e matérias de divulgação voltadas para o público-alvo, disponibilizadas na rede lógica interna (intranet).

O diagnóstico realizado junto ao setor administrativo institucional mostrou que a produção de resíduos é de cerca de $25 \mathrm{~m}^{3} /$ mês. Todo esse volume é coletado pelo serviço de limpeza pública municipal e destinado à área de depósito de resíduos sólidos da Região Metropolitana de Belém, popularmente conhecida como "Lixão do Aurá".

Para o planejamento da infraestrutura necessária para a implantação do PCSS procedeu-se a análise da planta do Campus de Pesquisa, para definir locais de instalação e a quantidade de lixeiras demandadas para a coleta seletiva, bem como a definição de uma área para acondicionamento de materiais recicláveis.

Foi identificada a demanda de cinqüenta e três (53) recipientes coletores de polietileno de média densidade, com capacidade para 50 litros, que foram distribuídos nos corredores externos das coordenações; 14 contêineres de polietileno com rodas em borracha maciça, com capacidade para 120 litros, para recolhimento de resíduos nas coordenações; e três contêineres de 1000 litros para armazenamento dos materiais recicláveis até o recolhimento pela Cooperativa de Catadores de Materiais Recicláveis (CONCAVES), que ocorre semanalmente.

Quanto ao local destinado para acondicionamento de material reciclável até a entrega para as associações e cooperativas envolvidas no programa, optou-se por uma área localizada ao lado da garagem institucional, justamente para facilitar o carregamento e transporte do material reciclável.

As prospecções de Cooperativas que atuam com reciclagem de resíduos tiveram como condição sine qua non de elegibilidade, a adequação das mesmas às prerrogativas estabelecidas no Decreto-Lei № 5.940, quais sejam: a) demonstrassem formalmente que eram exclusivamente constituídas por catadores de materiais recicláveis, que tivessem a catação como única fonte de renda; b) não possuíssem fins lucrativos; c) possuíssem infraestrutura para realizar a triagem e a classificação dos resíduos recicláveis descartados; d) apresentassem o sistema de rateio entre os associados e cooperados. Inicialmente foram selecionadas a Cooperativa dos Trabalhadores do Aurá (COOTPA), Cooperativa de Materiais Recicláveis (CONCAVES) e a Associação de Catadores de Águas Linda (ARAL). 


\subsection{Implantação e execução do Programa de Coleta Seletiva Solidária}

A Comissão Interna responsável pela implementação do PCSS foi encarregada das seguintes atribuições: ministrar cursos de capacitação e orientação para o pessoal que atuava na limpeza, funcionários da instituição e cooperativas; organizar campanhas de sensibilização internas e externas (cooperativa, escolas, comunidades) sobre a coleta seletiva solidária; locar cestos coletores de resíduos recicláveis; encaminhar os resíduos recicláveis para as cooperativas habilitadas e manter parceria com as cooperativas na troca de informações.

As ações de sensibilização do público-alvo tiveram início com a realização do 10 Seminário de Resíduos Sólidos, Coleta Seletiva e Responsabilidade Socioambiental, realizado no período de 9 a 11 de setembro de 2009. Este evento contou com a participação de 250 pessoas, envolvendo funcionários, estudantes, bolsistas, estagiários e catadores de resíduos. Foi considerado, de fato, o evento de lançamento do PCSS no Museu Paraense Emílio Goeldi.

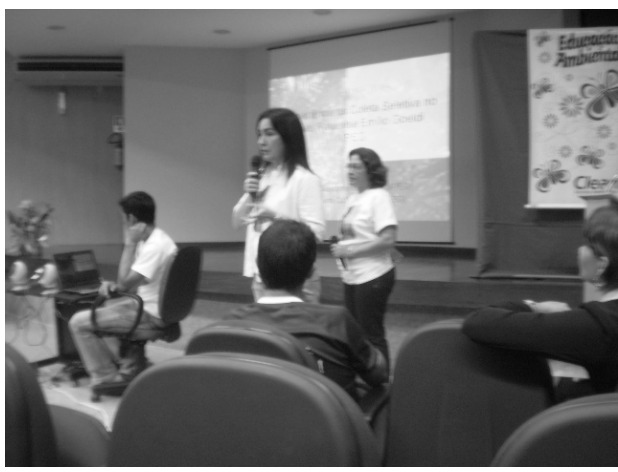

Figura 4: Palestra sobre a experiência da Coleta seletiva do Campus de Pesquisa do MPEG (Fonte: Diene Nascimento)

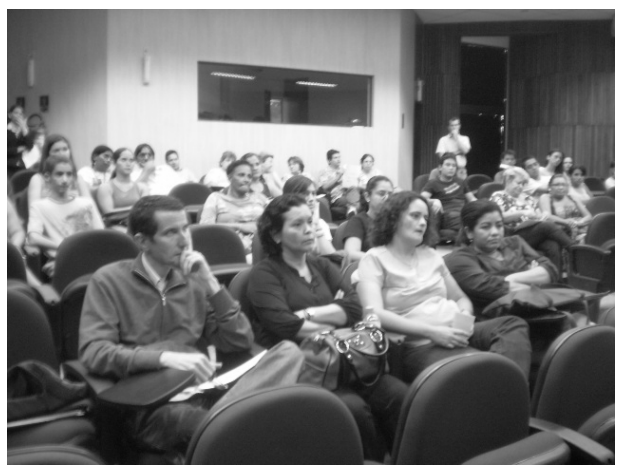

Figura 5: Participantes do seminário no Auditório do Campus de pesquisa do MPEG (Fonte: Diene Nascimento)

O Programa de Coleta Seletiva Solidária teve início com a distribuição de pequenas caixas de papelão decoradas com jornal, que foram alocadas nas salas dos departamentos de pesquisa, objetivando incentivar os pesquisadores a procederem à separação dos resíduos. A retirada desses recipientes se dava diariamente pelos trabalhadores da limpeza

Após dezoito (18) meses da implantação do programa, a instituição obteve recursos da ordem de dezesseis mil reais $(\mathrm{R} \$ 16.000,00)$ para aquisição de coletores adequados para as três bases físicas, os quais foram instalados a partir de setembro de 2009.

Posteriormente foram realizadas Oficinas de Educação Ambiental para funcionários, prestadores de serviços gerais, estudantes de graduação e pós-graduação, além de palestras sobre as experiências do PCSS no MPEG. Entre as atividades de extensão para o público externo, destacase a parceria com a Escola de Ensino Fundamental e Médio Mário Barbosa, contígua ao MPEG, com a finalidade de incentivá-los à implantação da coleta seletiva, onde foram desenvolvidas oficinas de artesanato com materiais recicláveis, contando com a participação de sessenta (60) alunos da $8^{a}$ série e professores responsáveis. (Figuras 6, 7) 
Rev. Elet. em Gestão, Educação e Tecnologia Ambiental (e-ISSN: 2236-1170)

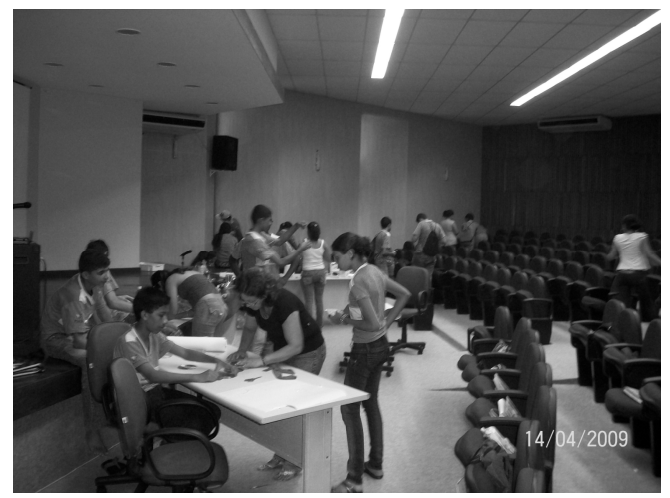

Figura 6: Oficina realizada com os alunos da escola Mário Barbosa no auditório do Campus de Pesquisa do MPEG (Fonte: Rifane Ruivo)

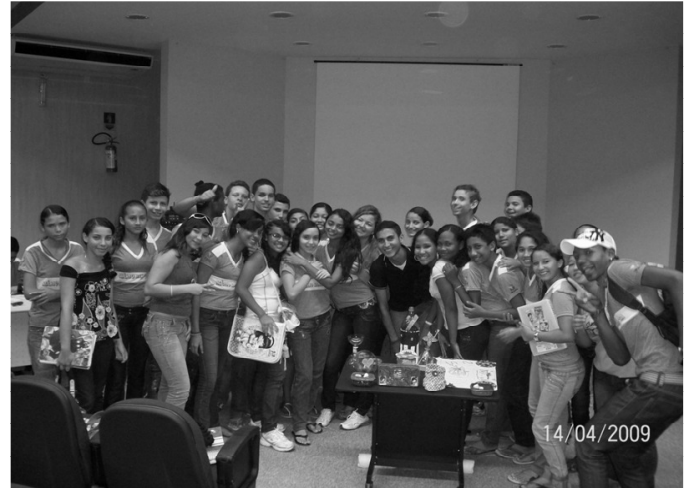

Figura 7: Alunos da escola Mário Barbosa no auditório do Campus de Pesquisa do MPEG (Fonte: Rifane Ruivo)

Foram realizadas entrevistas com trinta trabalhadores da Associação de Catadores de Águas Lindas, a fim de avaliar quais os benefícios obtidos após a implantação do programa, onde foi possível constatar que houve discreto aumento na renda familiar. Os relatos apontam também que os catadores são conscientes que os materiais recicláveis destinados às cooperativas e associações contribuem para diminuir a quantidade de resíduos encaminhados para os lixões a céu aberto e para retirar os catadores das ruas e dos lixões: o que aumenta a sua auto-estima e, consequentemente, melhora sua qualidade de vida.

Outra atividade desenvolvida foi o treinamento para os funcionários e prestadores de serviço terceirizados responsáveis pela limpeza da instituição, visto que são os responsáveis pelo acondicionamento dos materiais recicláveis nos setores internos e externos da instituição. 0 treinamento foi realizado nas três bases físicas do MPEG (Parque Zoobotânico, Campus de Pesquisa e Estação Científica Ferreira Penna), considerando sempre as particularidades de cada uma delas.

No período de 20 de março a 20 de maio de 2010 foram coletados dados mensais referentes à coleta seletiva de materiais recicláveis. Esses materiais foram classificados segundo as seguintes categorias: papel branco, papel colorido, papelão, cartonado, vidro, metais, plásticos (incluindo plásticos recicláveis como o Polietileno Tereftalato - PET, Polietileno de Alta Densidade - PEAD e Policloreto de Vinila - PVC).

\section{RESULTADOS E DISCUSSÂO}

\subsection{CARACTERIZAÇÕES DO MATERIAL RECICLÁVEL}

A caracterização qualitativa e quantitativa do material reciclável foi realizada para cada Coordenação (Ciências Humanas - CCH; Botânica - CBO; Zoologia - CZO; Ciências da Terra e Ecologia - CCTE; Informação e Documentação -CID) e Planejamento - CPA). Os resultados encontram-se sumarizados na Tabela 1. 


\section{REGEIAUFSM}

NASCIMENTO et al., v(10), no 10, p. 2233-2250, JAN-ABR, 2013.

Rev. Elet. em Gestão, Educação e Tecnologia Ambiental (e-ISSN: 2236-1170)

Tabela 1: Resultados por kg de materiais recicláveis por coordenações

\begin{tabular}{|c|c|c|c|c|c|c|c|c|c|c|c|c|c|c|c|c|c|c|c|c|c|}
\hline \multirow{3}{*}{$\begin{array}{l}\text { Tipologi } \\
\text { a }\end{array}$} & \multicolumn{20}{|c|}{ COORDENAÇÕES } & \multirow{3}{*}{$\begin{array}{l}\text { TOTAI } \\
\text { ANUA }\end{array}$} \\
\hline & \multicolumn{4}{|c|}{$\begin{array}{c}\text { Coordenação de Ciências } \\
\text { Humanas }\end{array}$} & \multicolumn{4}{|c|}{$\begin{array}{c}\text { Coordenação de } \\
\text { Botânica }\end{array}$} & \multicolumn{4}{|c|}{$\begin{array}{c}\text { Coordenação de } \\
\text { Zoologia }\end{array}$} & \multicolumn{4}{|c|}{$\begin{array}{c}\text { Coordenação de } \\
\text { Ciências da Terra e } \\
\text { Ecologia }\end{array}$} & \multicolumn{4}{|c|}{$\begin{array}{l}\text { Portaria + Prefeitura do } \\
\text { Campus + Almoxarifado }\end{array}$} & \\
\hline & $\mathbf{S}$ & $M$ & A & $\begin{array}{l}\% \\
\mathrm{~A}\end{array}$ & $S$ & $\mathbf{M}$ & A & $\begin{array}{l}\% \\
\mathrm{~A} \\
\end{array}$ & $S$ & $M$ & A & $\begin{array}{l}\% \\
\mathrm{~A}\end{array}$ & $\mathbf{S}$ & $\mathbf{M}$ & A & \begin{tabular}{|l|}
$\%$ \\
A \\
\end{tabular} & $S$ & $M$ & A & $\begin{array}{l}\% \\
\text { A }\end{array}$ & \\
\hline $\begin{array}{l}\text { Papel } \\
\text { Branco }\end{array}$ & $\begin{array}{c}15,7 \\
5\end{array}$ & 63 & 756 & $\begin{array}{c}59,6 \\
8\end{array}$ & 3,28 & 13,12 & $\begin{array}{c}157,4 \\
4\end{array}$ & $\begin{array}{l}13 \\
43\end{array}$ & \begin{tabular}{|c|}
8,5 \\
5
\end{tabular} & 34,2 & 410,4 & 25,21 & 1,63 & 6,52 & 78,24 & $\begin{array}{c}13,2 \\
4\end{array}$ & 1,6 & 6,4 & 76,8 & 8,76 & $\begin{array}{c}1478,8 \\
8\end{array}$ \\
\hline $\begin{array}{c}\text { Papel } \\
\text { Colorido }\end{array}$ & 3,2 & 12,8 & 153,6 & $\begin{array}{c}12,1 \\
3 \\
\end{array}$ & 1,52 & 6,08 & 72,96 & $\begin{array}{c}6,2 \\
2 \\
\end{array}$ & 4,8 & 19,2 & 230,4 & 14,16 & 1,8 & 7,2 & 86,4 & $\begin{array}{c}14,6 \\
2\end{array}$ & 0,52 & 2,08 & 24,96 & 2,85 & 568,32 \\
\hline Papelão & 3,95 & 15,8 & 189,6 & $\begin{array}{c}14,9 \\
7\end{array}$ & 11,6 & 46,4 & 556,8 & $\begin{array}{l}47, \\
50\end{array}$ & 6,4 & 25,6 & 307,2 & 18,87 & 2,32 & 9,28 & $\begin{array}{c}111,3 \\
6\end{array}$ & $\begin{array}{c}18,8 \\
4\end{array}$ & 1,45 & 5,8 & 69,6 & 7,94 & $\begin{array}{c}1234,5 \\
6\end{array}$ \\
\hline Plástico & 3,25 & 13 & 156 & $\begin{array}{c}12,3 \\
2\end{array}$ & 3,7 & 14,8 & 177,6 & $\begin{array}{l}15 \\
15\end{array}$ & $\begin{array}{c}8,1 \\
2\end{array}$ & 28,48 & 341,76 & 21,00 & 3,38 & 13,5 & 162 & $\begin{array}{c}27,4 \\
1\end{array}$ & 6,98 & $\begin{array}{c}27,9 \\
2\end{array}$ & $\begin{array}{c}335,0 \\
4\end{array}$ & $\begin{array}{c}38,2 \\
0\end{array}$ & 1172,4 \\
\hline Vidro & - & - & - & - & 0,88 & 3,52 & 42,24 & $\begin{array}{c}3,6 \\
0\end{array}$ & - & - & - & - & 0,8 & 3,2 & 38,4 & 6,50 & 1,2 & 4,8 & 57,6 & 6,57 & 138,24 \\
\hline Metal & 0,13 & 0,52 & 6,24 & 0,49 & 0,9 & 3,6 & 43,2 & $\begin{array}{c}3,6 \\
9\end{array}$ & 2,8 & 11,2 & 134,4 & 8,26 & 1,18 & 4,72 & 56,64 & 9,58 & 3,73 & $\begin{array}{c}14,9 \\
2\end{array}$ & $\begin{array}{c}179,0 \\
4\end{array}$ & \begin{tabular}{|c|}
20,4 \\
2
\end{tabular} & 419,52 \\
\hline Pet & 0,11 & 0,44 & 5,28 & 0,42 & 1,84 & 7,36 & 88,32 & $\begin{array}{c}7,5 \\
3\end{array}$ & $\begin{array}{c}2,5 \\
7\end{array}$ & 10,28 & 123,36 & 7,58 & 0,43 & 1,72 & 20,64 & 3,49 & 2,56 & $\begin{array}{c}10,2 \\
4\end{array}$ & $\begin{array}{c}122,8 \\
8\end{array}$ & $\begin{array}{c}14,0 \\
1\end{array}$ & 360,48 \\
\hline $\begin{array}{c}\text { Cartona } \\
\text { do }\end{array}$ & - & - & - & - & 0,7 & 2,8 & 33,6 & $\begin{array}{c}2,8 \\
7\end{array}$ & $\begin{array}{c}1,6 \\
7\end{array}$ & 6,68 & 80,16 & 4,92 & 0,78 & 3,12 & 37,44 & 6,33 & 0,23 & 0,92 & 11,04 & 1,26 & 162,24 \\
\hline Total & \begin{tabular}{|c|}
26,3 \\
9
\end{tabular} & \begin{tabular}{|c|}
105,5 \\
6 \\
\end{tabular} & $\begin{array}{c}1266,7 \\
2 \\
\end{array}$ & 100 & $\begin{array}{c}24,4 \\
2\end{array}$ & 97,68 & \begin{tabular}{|c|}
1172 \\
16 \\
\end{tabular} & 100 & $\begin{array}{l}34, \\
91\end{array}$ & $\begin{array}{c}135,6 \\
4\end{array}$ & $\begin{array}{c}1627,6 \\
8\end{array}$ & 100 & $\begin{array}{c}12,3 \\
2\end{array}$ & \begin{tabular}{|c|}
49,2 \\
6
\end{tabular} & $\begin{array}{c}591,1 \\
2\end{array}$ & 100 & 18,27 & \begin{tabular}{|c|}
73,0 \\
8 \\
\end{tabular} & $\begin{array}{c}876,9 \\
6\end{array}$ & 100 & $\begin{array}{c}5534,6 \\
4\end{array}$ \\
\hline
\end{tabular}

S-Peso Semanal (kg) M-Peso Mensal (kg)

A - Peso Anual (kg)

\%A - Percentual Anual 


\section{REGETATFM}

NASCIMENTO et al., v(10), no 10, p. 2233-2250, JAN-ABR, 2013.

Rev. Elet. em Gestão, Educação e Tecnologia Ambiental (e-ISSN: 2236-1170)

A quantidade total de material reciclável produzido no âmbito da instituição foi de $5.534,64$ kg, Desse total (Figura 8), a Coordenação de Zoologia contribuiu com 29,41\% seguia pela Coordenação de Ciências Humanas (22,89\%), Coordenação de Botânica (21,18\%), Portaria + Prefeitura + Almoxarifado $(15,84 \%)$ e, finalmente, a Coordenação de Ciências da Terra e Ecologia (10,68\%).

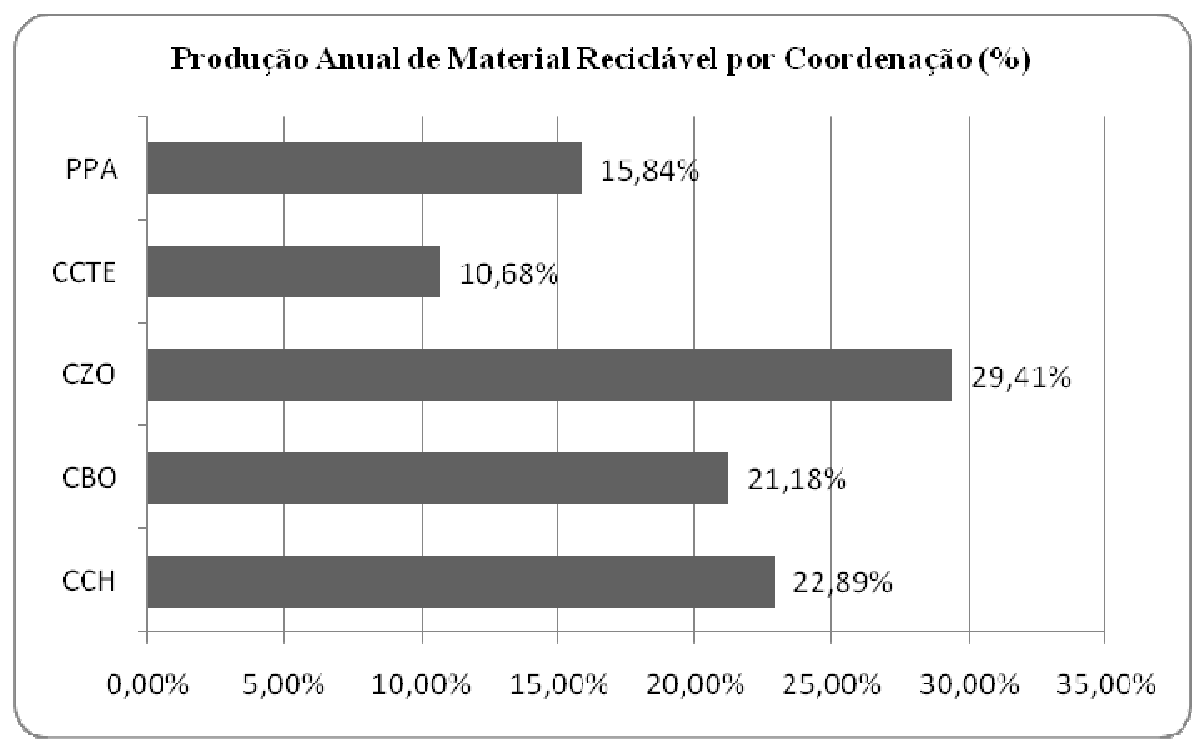

Figura 8: Percentual de produção de material reciclável por Coordenação

O fato de a Coordenação de Zoologia (CZO) produzir a maior quantidade de materiais acumulado se dá pelo maior número de funcionários, bolsistas e estagiários que freqüentam esta coordenação de pesquisa. O CCTE foi à coordenação que produziu a menor quantidade de material e isso se dá pelo fato de apresentar um contingente menor de funcionários, bolsistas e estagiários, mas, principalmente. Por uma melhor aceitação e colaboração com o programa de coleta seletiva, no que tange o melhor reaproveitamento (Ex. reutilização das folhas de papel como bloco de anotação, impressão de textos para leituras nas costas do papel usado etc.) e economia no uso dos mesmos.

No aspecto qualitativo o papel branco foi o material reciclável com maior taxa de produção anual na instituição (Figura 9), perfazendo $26,72 \%(1.478,88 \mathrm{~kg})$ vindo a seguir o papelão $(22,31 \%$ - $1.234,56 \mathrm{~kg})$, plástico $(21,18 \%$ - $1.172,4 \mathrm{~kg})$, papel colorido $(10,27 \%$ $568,32 \mathrm{~kg})$, metal $(7,58 \%$ - 419,52 kg), pet $(6,51 \%$ - 360,48 kg), cartonado $(2,93 \%$ - 162,24 kg) e vidro $(2,50 \%-138,24 \mathrm{~kg})$. 


\section{REGEIAUFSM}

NASCIMENTO et al., v(10), no 10, p. 2233-2250, JAN-ABR, 2013.

Rev. Elet. em Gestão, Educação e Tecnologia Ambiental (e-ISSN: 2236-1170)

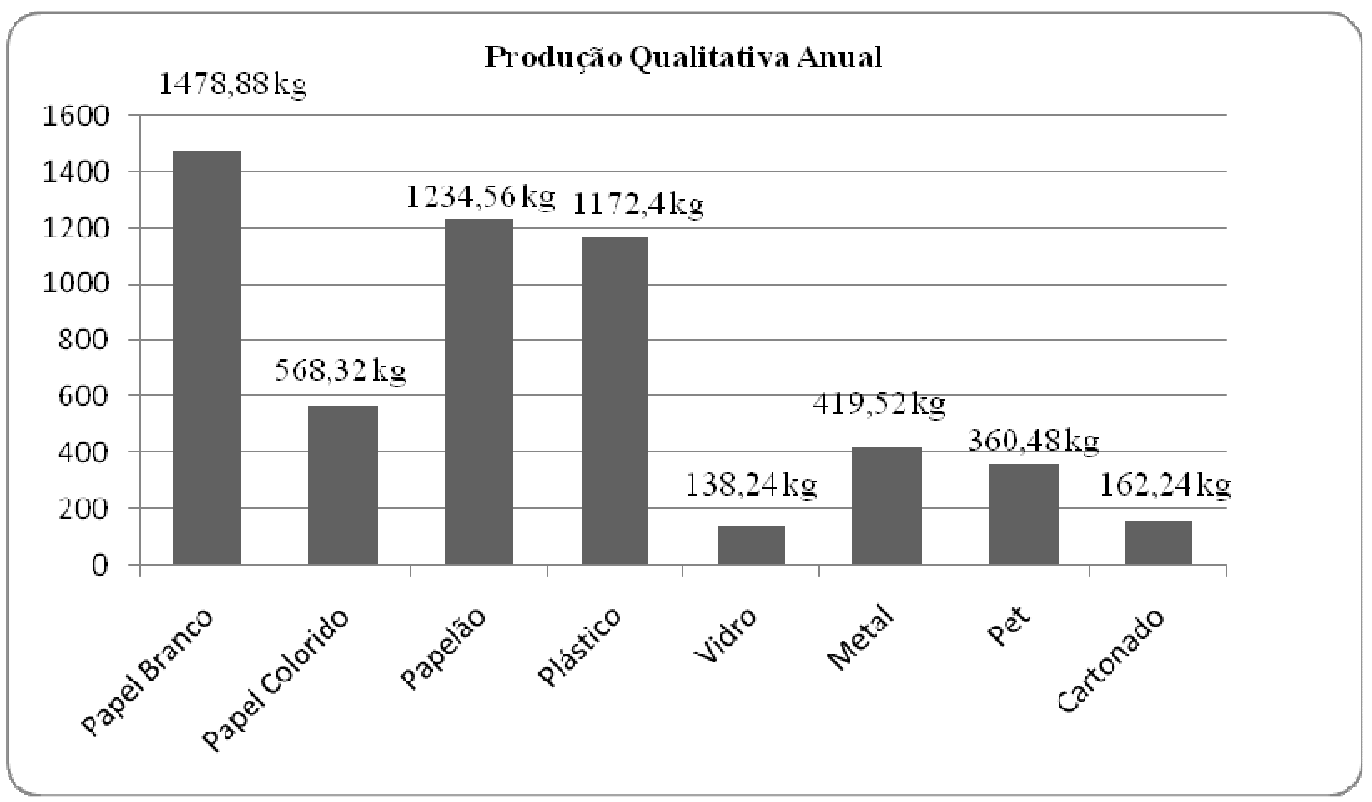

Figura 9: Produção qualitativa anual de material reciclável no Campus de Pesquisa do MPEG

O fato de o papel branco ser o material reciclável com maior produção procede, pois o MPEG é uma instituição de pesquisa e, como tal, o uso do papel se dá em grande escala. Os demais materiais como metal, vidro, pet e cartonado aparecem como uma quantidade continua devido à existência de restaurante na instituição e pelo fato de que alguns funcionários selecionarem seus materiais recicláveis em casa e trazerem para o MPEG, haja vista a existência da entrega a cooperativa e pelo fato de não existir arrecadação da coleta seletiva na cidade de Belém.

Tomando por base a tabela de preços praticados no mercado de Belém (Tabela 2) foi realizada a valorização do material reciclável produzido ao longo do ano na instituição.

\begin{tabular}{|l|r|}
\hline \multicolumn{2}{|l|}{ Preço do material reciclado por Kg } \\
\hline Tipologia & Preço (R\$) \\
\hline Papel Branco & 0,16 \\
\hline Papel Colorido & 0,05 \\
\hline Papelão & 0,08 \\
\hline Plástico & 0,45 \\
\hline Vidro & 0,40 \\
\hline Alumínio & 1,20 \\
\hline Pet & 0,40 \\
\hline Cartonado & 0,40 \\
\hline
\end{tabular}

Tabela 2: Preço de venda por material Fonte: Cooperativa- CONCAVES

Conforme demonstrado na Figura 10, o quantitativo de material reciclável gera valores anuais da ordem de $\mathrm{R} \$ \mathbf{5 . 5 3 4 , 6 4}$ (cinco mil, quinhentos e trinta e quatro reais e 


\section{REGETATFS}

NASCIMENTO et al., v(10), no 10, p. 2233-2250, JAN-ABR, 2013.

Rev. Elet. em Gestão, Educação e Tecnologia Ambiental (e-ISSN: 2236-1170)

sessenta e quatro centavos), sendo a Coordenação de Zoologia responsável por aproximadamente $21,18 \%$ dessa renda.

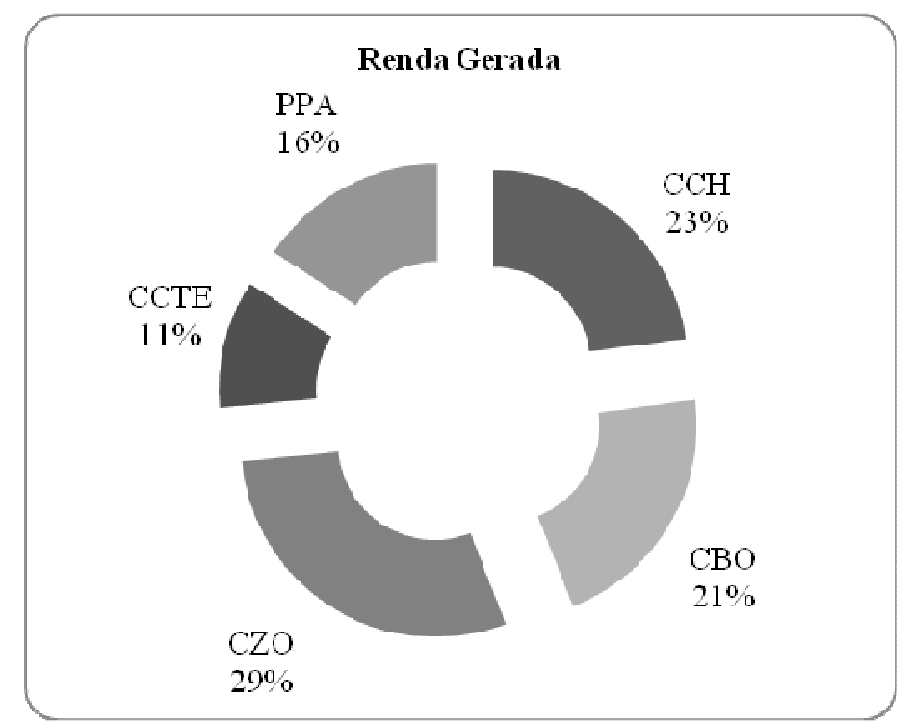

Figura 10: Participação das coordenações institucionais na geração de renda a partir da carga de material reciclável coletada anualmente

Em termos mensais o valor gerado é pouco significativo $(R \$ 138,27)$, equivalendo a pouco mais de $20 \%$ do salário mínimo vigente no país. Infelizmente não há como avaliar o impacto desse montante na arrecadação mensal das associações de catadores que recebem o material e, tão pouco, no rendimento mensal de seus associados. É importante frisar que essas amostras são relevantes, porém não devemos deixar de mencionar que a quantidade de misturas de resíduos comuns e orgânicos sob os materiais recicláveis separados são constante, deixando de aumentar a valoração para as cooperativas.

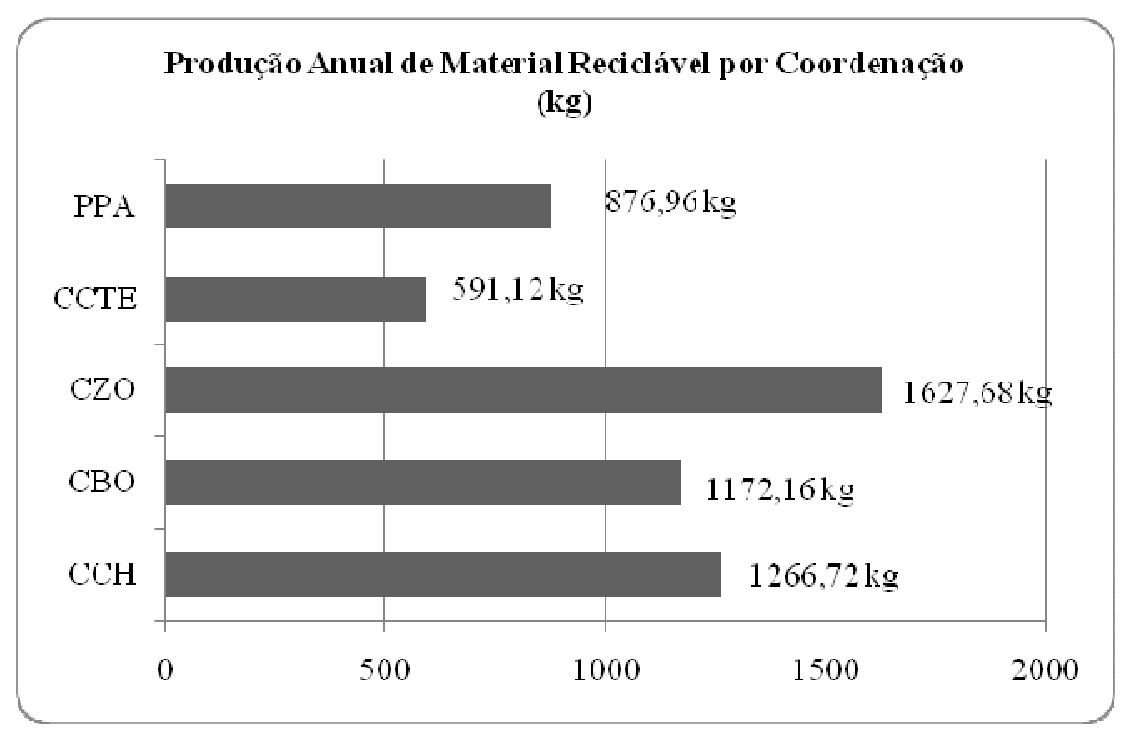

Figura 11 Resultado por peso de cada coordenacao 


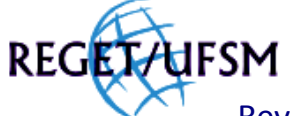

NASCIMENTO et al., v(10), no 10, p. 2233-2250, JAN-ABR, 2013.

Rev. Elet. em Gestão, Educação e Tecnologia Ambiental (e-ISSN: 2236-1170)

Um dos grandes desafios enfrentado pela instituição no decorrer da implantação do programa é desenvolver estratégias que contribuam para o fortalecimento do mesmo, assim como sua extensão para suas demais bases, como, por exemplo, no Parque Zoobotânico, e na Estação Científica Ferreira Penna (Caxiuanã-Pa).

Dificuldades foram enfrentadas para a escolha das cooperativas e associações responsáveis pelo recolhimento dos materiais recicláveis da instituição, pois as mesmas necessitavam estar legalizadas, porém as mesmas enfrentam entraves como a falta de recursos financeiros para se legalizarem.

Outra grande dificuldade enfrentada pela instituição é fazer com que funcionários, prestadores de serviços terceirizados, estudantes e bolsistas se adéqüem às regras da coleta seletiva, pois apesar dos containeres serem padronizados, ainda ocorre à mistura dos resíduos orgânicos com os recicláveis. Desta forma, faz-se necessário desenvolver campanhas e treinamentos constantes para todos freqüentadores do campus de pesquisa e o comprometimento com a importância da separação dos materiais recicláveis no MPEG e sua destinação a cooperativa que esteja adequada a receber os materiais.

\section{CONCLUSÃO}

A coleta seletiva solidária tem um impacto ambiental bastante positivo no Campus de Pesquisa do MPEG, sobretudo por contribuir para mudanças de hábitos culturais e fomentar maior percepção e participação dos funcionários (do quadro fixo e terceirizado), pesquisadores, alunos, bolsistas e estagiários, o que serviu de base para a extensão do programa às outras bases físicas da instituição.

A metodologia aplicada para o desenvolvimento do trabalho foi correspondente ao esperado, porem se faz necessários novos levantamento para relacionar novos dados a fim de verificar o comportamento dos atores na aplicabilidade do programa.

Os resultados variaram não somente pelas atividades desenvolvidas em cada Coordenação, como, também, em decorrência da quantidade do pessoal fixo e flutuante que freqüentam as unidades estudadas.

Quanto ao preço, em se tratando de materiais recicláveis varia de acordo com o negociador, pois o material prensado e limpo vale mais, enquanto que o material vindo de coletores vale menos por não ter um mercado certo. A grande dificuldade enfrentada pela cooperativa CONCAVES, segundo o relato do presidente é que as vendas são feitas para atravessadores que, ao final, são mais beneficiados que a cooperativa.

Outro ponto negativo relatado foi quanto o baixo impacto na renda da cooperativa e individual de cada catador, pois o valor para todos os $\mathrm{kg}$ de materiais recicláveis é muito baixo na cidade de Belém, alem dos mesmos não realizarem venda direta, ou seja a presença do intermediário no processo de compra do material junto aos catadores contribui para o baixo lucro da cooperativa, alem de não possuírem equipamentos (Esteira, prensa), o que poderia valorizar seus materiais.

Por fim, é proposta do Programa a intensificação da experiência da Coleta Seletiva Solidária, com ações externas, a fim de promover a níveis eficazes a gestão sustentável dos resíduos recicláveis produzidos em todas as bases do Museu Paraense Emílio Goeldi, não somente para cumprir as diretrizes do Decreto Federal, mas especialmente, para 
REGETHFSM

NASCIMENTO et al., v(10), no 10, p. 2233-2250, JAN-ABR, 2013.

Rev. Elet. em Gestão, Educação e Tecnologia Ambiental (e-ISSN: 2236-1170)

transformar e fomentar uma cultura compromissada com a inclusão social de catadores de materiais recicláveis e suas famílias com o ambiente natural.

\section{REFERÊNCIAS}

AGUIAR, R.A.R. de. Direito do Meio Ambiente e Participação Popular. MMA/IBAMA. Brasília. 1994, p. 109.

ANDRADE, Tânia \& JERONIMO, Valdith. Meio Ambiente: Lixo e Educação Ambiental. João Pessoa: Grafset, 2004.

BIANCHINI, T. Coleta seletiva é a saída. Ecologia e Desenvolvimento, Rio de Janeiro, a. 11, n. 96, p. 20, set. 2001.

BRASIL. Decreto no 5.940, de 25 de outubro de 2006. Institui a separação dos resíduos recicláveis descartados pelos órgãos e entidades da administração pública federal direta e indireta, na fonte geradora, e a sua destinação às associações e cooperativas dos catadores de materiais recicláveis. Diário Oficial, Poder Executivo. Brasília: DOU de 26/10/2006.

BRASIL, Portal. Lei do tratamento do lixo é regulamentada, 2011. Disponível em <www Brasil.gov.br>. Acesso em julho de 2011

BLEY JR, C. Lixo no Brasil e no Mundo. Seminário Nacional de Resíduos Sólidos e Limpeza Urbana, São Paulo, set. 2001.

CALDERONI, S. Os bilhões perdidos no lixo. 3. ed. São Paulo: Humanitas, 1999.

CEMPRE. Guia da coleta seletiva de lixo. São Paulo, 1999. CD-ROM

COZETTI, N. Lixo: marca incômoda da modernidade. Ecologia e Desenvolvimento, Rio de Janeiro, a. 11, n. 96, p. $10-17$, set. 2001.

ELETROBRÁS. 2010. Responsabilidade Social. Disponível em <www eletrobras. / Lum's 57511 E 7C 7D PTBRIE.htm>. Acesso em novembro de 2011.

GONÇALVES, Pólita. A reciclagem Integradora dos aspectos ambientais, Sociais e Econômicos. Rio de Janeiro. DP. Fase 2003

GRADVOHL, A. Reciclando o lixo. Fortaleza: Editora Verdes Mares, 2001, p. 104.

LOUREIRO, C. F. B. Trajetória e Fundamentos da Educação Ambiental. São Paulo, Cortez, 2006.

MEIRA, Marcio. A Rocinha do Museu. Jornal O Liberal. Edição outubro de 1986. Caderno Atualidades.

MUSEU PARAENSE EMILIO GOELDI. Coordenação de Ciência da Terra e Ecologia Relatório de atividades 2007. Belém, 2008, p.145.

NASCIMENTO FILHO, R.L.G. do. O lixo lançado ao Rio pelo Transporte Comercial no percurso Belém-BrevesBelém: Uma proposta de Educação Ambiental. NUMA/UFPa. 1996. Belém-PA.

NEIVA, A. Reciclagem cresce no Brasil. Ecologia e Desenvolvimento, Rio de Janeiro, a. 11, n. 96, p.18-19, set. 2001. 


\section{REGETAUFM}

NASCIMENTO et al., v(10), no 10, p. 2233-2250, JAN-ABR, 2013.

Rev. Elet. em Gestão, Educação e Tecnologia Ambiental (e-ISSN: 2236-1170)

VILHENA, A.; D’ALMEIDA, M. L. O. Processamento do lixo: segregação de materiais. In: (coordenadores). Lixo municipal: manual de gerenciamento integrado. São Paulo: IPT/CEMPRE, 2000. p. 81-89. Disponível em: $<w w w$. recicologias.com.br/coleta.html >. Acesso em junho de 2011

VIEIRA, A.L. Reciclagem e sociedade: uma abordagem social de analise do ciclo de vida das latas de aluminio. Belem: EDUFRA, 2006. 